\title{
La ambiciosa meta de Salvador Díaz Mirón
}

SUele considerarse, admirativamente, no sólo como obligada meta, $\checkmark$ en el recorrido poético de Díaz Mirón, el verso en el que - unidad perfecta, libre ya de asonancias- acabó por eliminar también las vocales tónicas repetidas.

Se habla con elogio de esa innovación en la técnica del verso: limitación que voluntariamente se impuso para superar dificultades en la etapa que sigue a Lascas, donde ya había vencido otras.

Por haber aumentado las exigencias para consigo, se dice, el poeta que aspiraba a la mayor perfección formal, 1legó a ser literariamente estéril, en sus últimos años.

En la revolución romántica, la polimetría rompe la unidad del poema. Dan el siguiente paso los precursores del Modernismo, al independizar la estrofa, cuando hacen de ella un eslabón - de oroque puede cambiarse de sitio sin que la cadena lírica se corte.

Los poetas modernistas dan otro paso hacia el verso - y aun el vocablo- autónomo, al romper la unidad de la estrofa: el verso, hasta entonces unidad métrica inseparable del conjunto en una composición, deja de estar uniformemente sometido a las leyes de acento - ritmo- y rima.

Díaz Mirón había explorado sucesivamente esos nuevos rumbos, en los períodos de su evolución anteriores a Lascas, donde llega al verso libre.

Próximo al ocaso, las preocupaciones del poeta vuelven a centrarse en algunos aspectos de técnica literaria: de selección de voca- 
blos, no sólo por la eufonía particular de cada uno, sino por la del verso, que le preocupa en su unidad, ya no como elemento integrante de la estrofa, parte del todo.

Revela eso el contenido de la carta relativa al poema "Los peregrinos", que publicó en España Rufino Blanco-Fombona, a raíz de la muerte de Díaz Mirón. En ella habla del cuidado con que trabajó esa poesía, en la cual desarrolla, en molde romántico -el cuarteto alejandrino de rimas cruzadas, oxítonas en los versos pares-, un tema bíblico, antes tratado por los pintores, procedente de San Lucas.

Comienza Díaz Mirón por advertir: "La elijo, no por preferirla, que me parece un poco floja, sino por cuanto ella da pleno testimonio de cierta técnica que vengo ensayando como estudio de eufonía y léxico". Mayor importancia concede al hecho de que "no hay alli ripios, ni repetida ninguna vocal acentuada, tónica $\mathfrak{u}$ ortográficamente, en el mismo verso..."

En el desarrollo del tema, anticipa la revelación del peregrino de Emaus, que puclo reservar para la última estrofa. (Esta, en vez de las rimas cruzadas de los anteriores cuartetos, ofrece tres versos monorrimos, y el final, oxítono, rima con el último de la precedente.) Los dos apóstoles se sienten estimulados, en el camino, por la presencia del Redentor, resurrecto. El poeta no se limitó a sugerir únicamente lo que el final confirma: lo descubre al lector, que, por lo demás, lo sabía desde antes. A eso alude quizás Díaz Mirón, cuando habla de lo débil del poema, en el que hay delicados toques de paisajista - alguno de ellos, modificado por él posteriormente- y una distribución de voces esdrújulas acertada, como en el verso que dice:

en la impúdica gloria de tan pérfido abril.

Lo descriptivo alterna, igual que en otras poesías diazmironianas, con pasajes en que se desliza lo subjetivo, y alguna reflexión, como esta:

Ocurre que aun los buenos olvidan de congoja que la virtud estriba en creer y esperar. 
Las preocupaciones de tipo técnico, por el logro de la eufonía de cada verso, aislado en su perfecta musicalidad, sin duda apartaron la atención del poeta, de preocupaciones de otra índole. Su autocrítica que contiene esa carta, ha contribuído también a que la atención de los lectores se fije sólo en este aspecto, y compruebe lo afirmado por aquél, en cada uno de los versos del poema.

Según la preocupación dominante en él, tiende el poeta a considerar cada verso de "Los peregrinos" aisladamente, por st1 valor musical, eufónico. Para examinarlo sin prisa, conviene reproducir íntegro el poema, después de poner números romanos al frente de cada una de sus estrofas:

Ambos justos recorren la campiña serena y van por el camino conducente a Emaús. Encórvanse agobiados por una misma pena: el desastre del Gólgota, la muerte de Jesús.

II

E1 soplo de la tarde perfuma y acaricia, y aquellos transeúntes hablan de la pasión. $\mathrm{Y}$ en cada tosco pecho desnudo de malicia, se ve saltar la túnica, latir el corazón.

III

A los cautos discípulos la fe insegura enoja, y los míseros dudan, como Pedro en el mar. Ocurre que aún los buenos olvidan de congoja que la virtud estriba en creer y esperar.

IV

Cadena de montículos, cuadros de sembradura y sangrando en la hierba la lis y el ababol; y entre filas de sauces de pródiga verdura, la vía que serpea encharcada de sol. 
$\mathrm{v}$

La pareja trasuda, compungida y huraña, en la impúdica gloria de tan pérfido abril; y el susurro que suena en las hojas amaña siseos cual de turba profanadora $y$ vil.

VI

Los pobres compañeros se rinden al quebranto, y de súbito miran a su lado al Señor... ¡Pero los ojos, turbios al arbitrio del Santo, se confunden, no aciertan a pesar del amor!

VII

El Maestro, venido en sazón oportuna, acrimina y exhorta, más dulce que cruel; y enseñando cautiva, i pues en la voz aduna armonía y fragancia y resplandor y miel!

VIII

$\mathrm{Y}$ pregunta y responde a la gente sencilla... Marcha rizos al viento y razona la cruz. ¡El pie bulle y se torna, y la planta le brilla como al remo la pala, que surgida es de luz!

IX

Los andantes arriban al villorrio indolente, que salubre y bucólico huele a mística paz; y las mozas, que acuden al pretil de la fuente, los acogen con risas de indiscreto solaz.

$\mathrm{x}$

$\mathrm{Y}$ los tres se introducen en humilde casona... ¡Y en la rústica mesa, la Sagrada Persona parte, bendice y gusta la caliente borona... y disípase luego, como el humo fugaz!

Se ha dado, en realidad, una importancia mayor a los resultados de ese esfuerzo, en relación con las limitaciones que el poeta se impuso, y las dificultades creadas por él, para vencerlas. 
Ciertamente su rigor técnico excesivo le obligó a elegir vocablos en que no se repitieran las vocales tónicas en ei mismo verso. La atención se concentra, así, en cada alejandrino, y olvida transitoriamente los restantes; mas si del verso se pasa a la estrofa, es otro el resultado.

El oído casi no advierte, en voces plenas o esdrújulas, contiguas, la reiteración eludida, ni la involuntaria repetición de una vocal acentuada; mas sí la percibe al final de palabras de terminación aguda y en los monosílabos, ya que entonces se producen asonancias.

Si se examina en conjunto la composición, se advierte que no sólo hay idénticas vocales acentuadas, pues aparecen las asonancias con frecuencia, en versos tan próximos, que es fácil percibirlas.

El examen de algunos de ellos, permite confirmarlo.

La voz inicial de la composición, ambos, tiene las mismas vocales tónica - $a-\mathrm{y}$ final $-o-$ que la palabra con la cual concluye el primer hemistiquio del tercer verso de la misma estrofa: agobiados. La posición de una y otra, hace más perceptible la asonancia.

En el segundo cuarteto y en versos contiguos, segundo y tercero, se encuentran dos voces que también riman imperfectamente: hablan y cada. Las mismas vocales, tónica y final, se dan en ellas: ... hablan de la pasión.

$\mathrm{Y}$ en cada tosco pecho...

La tercera estrofa presenta asonancias en sus cuatro versos: insegura (19) rima con dudan $\left(2^{\circ}\right)$; Pedro $\left(2^{\circ}\right)$ con buenos $\left(3^{\circ}\right)$ y olvidan (3\%) con estriba (4\%).

De modo semejante, en la cuarta estrofa, aparecen las asonancias entre cuadros $\left(1^{\circ}\right)$ y sangrando $\left(2^{\circ}\right)$ y entre filas $\left(3^{\circ}\right)$ y via $\left(4^{\circ}\right)$.

En la quinta estrofa riman imperfectamente pareja (19) y suena $\left(3^{\circ}\right)$; trasuda $\left(1^{\circ}\right)$, impidica $\left(2^{\circ}\right)$ y turba $\left(3^{\circ}\right)$; hojas $\left(3^{\circ}\right)$ y profanadora (4\%).

En la sexta estrofa son idénticas las vocales tónica y final de quebranto $\left(1^{\circ}\right)$ y lado (2\%) y de súbito $\left(2^{\circ}\right)$ y turbios $\left(3^{\circ}\right)$, respectivamente.

En la séptima, aparecen las asonancias de cruel (2\%) con pues (3) y de cautiva (3) con armonía (4ㅇ). 
En la octava, riman de modo imperfecto las voces marcha $\left(2^{\circ}\right)$

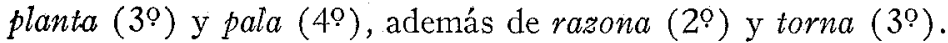

En la penúltima estrofa pueden hallarse asonancias entre arriban

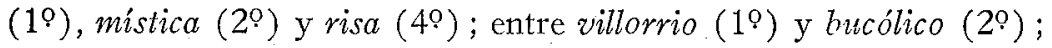
indolente $\left(1^{\circ}\right)$ y huele $\left(2^{\circ}\right)$ salubre $\left(2^{\circ}\right)$ y acuden ( $\left.3^{\circ}\right)$.

En el último cuarteto, rística (2०) y gusta (3) tienen la vocal tónica $-u-y$ la final $-a$ - idénticas.

Se ha prescindido de mencionar aquí otras asonancias menos próximas.

Como no relacionó entre sí los versos de una misma estrofa, menos aún pensó en tener presentes, para la perfecta eufonía total, los versos contiguos, en las demás estrofas.

Si se examina el verso final de cada cuarteto y aquel con el cual comienza el inmediato, se advierten otras repeticiones de vocales idénticas, prosódicamente acentuadas. Hay asonancias entre las voces desastre, al final de la primera estrofa, y tarde, al principio de la contigua; y túnica, al final de ésta, e insegura, en el primer verso de la tercera.

Las palabras vía, serpea y encharcada, del verso final de la cuarta estrofa, tienen sus respectivas asonancias en compungida, pareja y huraña, del verso con que se inicia la estrofa siguiente.

Siseos (v) y compañeros (VI); amor (VI) y razón (VII) ; armonía (VII) y sencilla (VIII), y surgida (VIII) y arriban (IX) son voces que riman entre sí, con rima imperfecta, en versos contiguos.

En resumen, no hay cuarteto de "Los peregrinos" exento de asonancias -inadvertidas, no intencionales--, y en alguno de ellos se presentan en versos contiguos. El esfuerzo de Díaz Mirón resulta, pues, contraproducente para la perfección total del poema.

Concentrada la atención del poeta en cada verso, para evitar en él la repetición de vocales "acentuadas tónica u ortográficamente", no pudo relacionarlo con los demás de la misma estrofa y de las vecinas.

Ambicioso, para lograr la perfección, el poeta forjó a su imagen cada verso, aislado, en un orgulloso egocentrismo.

De ese modo logró solamente hacer versos casi perfectos en su eufonía, como unidades aisladas, pues olvidó, al proceder asi, que 
era inevitable relàcionar cada unidad con las inmediatas, y tomar en cuenta los versos precedentes y subsecuentes.

Eludió un peligro; mas sin pensar en otros riesgos que acechaban, próximos: las unidades rítmicas, aisladamente perfectas, dentro de esa técnica exigente, chocaron entre sí, dañándose unas a otras, sin que él pudiera advertirlo.

Su estética demasiado rigurosa, con la innovación intentada, logró algo equivalente al autismo del verso; mas no por ello dejó de hallarse éste supeditado a los colindantes.

Francisco Monterde 
